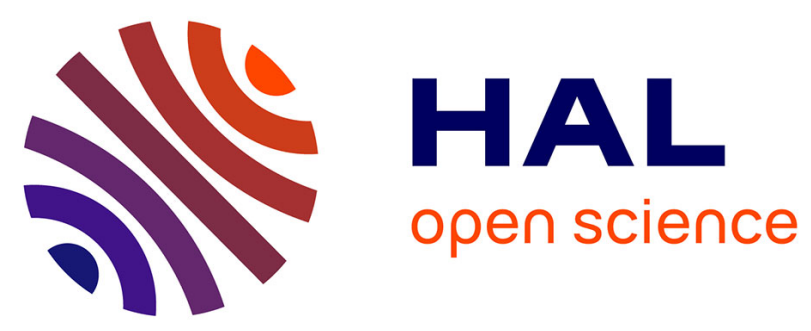

\title{
Measurement of the Effects of High-Pressure Laser Shocks on Metallic Targets
}

\author{
T. de Resseguier, S. Couturier, J. David, G. Niérat
}

\section{To cite this version:}

T. de Resseguier, S. Couturier, J. David, G. Niérat. Measurement of the Effects of High-Pressure Laser Shocks on Metallic Targets. Journal de Physique IV Proceedings, 1997, 07 (C3), pp.C3-205-C3-210. 10.1051/jp4:1997337 . jpa-00255494

\section{HAL Id: jpa-00255494 https://hal.science/jpa-00255494}

Submitted on 1 Jan 1997

HAL is a multi-disciplinary open access archive for the deposit and dissemination of scientific research documents, whether they are published or not. The documents may come from teaching and research institutions in France or abroad, or from public or private research centers.
L'archive ouverte pluridisciplinaire HAL, est destinée au dépôt et à la diffusion de documents scientifiques de niveau recherche, publiés ou non, émanant des établissements d'enseignement et de recherche français ou étrangers, des laboratoires publics ou privés. 


\title{
Measurement of the Effects of High-Pressure Laser Shocks on Metallic Targets
}

\author{
T. De Rességuier, S. Couturier, J. David* and G. Niérat*
}

Laboratoire de Combustion et de Détonique, UPR 9028 du CNRS, ENSMA, Site du Futuroscope, BP. 109, 86960 Futuroscope cedex, France

* Centre CEA de Limeil-Valenton, EIL-DLP-MOE, 94195 Villeneuve-St-Georges cedex, France

\begin{abstract}
Piezoelectric measurements have been performed behind metallic samples submitted to short laser shocks of intensities up to $7 \mathrm{TW} / \mathrm{cm}^{2}$, using recently developed polymeric transducers. Some records exhibit a recompression indicating spall damage, confirmed by post-test microscopic observations. Computations involving a laser-matter interaction model and a wave-propagation code lead to a correct agreement on the gauge records. They indicate peak pressures of 7 to $150 \mathrm{GPa}$ in the targets. A phenomenological spall model of the literature provides an approximated description of the relaxation associated with spallation, and a fair estimate of the damage level and location in the target.
\end{abstract}

Résumé. Des mesures piézoélectriques ont été réalisées à l'arrière de cibles métalliques soumises à des chocs laser brefs d'intensité pouvant atteindre $7 \mathrm{TW} / \mathrm{cm}^{2}$; au moyen de capteurs polymériques. Certains signaux comportent une recompression traduisant un écaillage des cibles, confirmé par un examen post-test. La simulation des expériences avec un modèle d'interaction laser-matière et un code de propagation est en accord correct avec les enregistrements. Elle indique des pressions maximales de 7 à $150 \mathrm{GPa}$ dans les cibles. Un modèle phénoménologique d'écaillage fournit une description approximative de la relaxation associée à la rupture, et de la distribution de l'endommagement dans la cible.

\section{INTRODUCTION}

Over recent years, high-power pulsed lasers have appeared as an appropriate laboratory tool to generate high dynamic pressures in condensed matter, offering the possibility of adjusting over a very wide range the temporal shape, the duration and the amplitude (up to a few Mbar) of the load applied onto the irradiated sample. For instance, they have been widely used to investigate spallation of solid materials [1-6]. Nevertheless, one prerequisite for the analysis of any shock experiment is a satisfying knowledge of the pressure profile induced in the target. Thus, theoretical and numerical models have been developed to describe the conversion of the laser light pulse into a pressure pulse, and instrumented laser-shock experiments are needed to assess the predictive capability of those models.

In this paper, we report piezoelectric measurements at the rear surface of metallic targets submitted to laser-driven shocks over a wide range of laser irradiances. The use of recently developed polymeric transducers [7-10] allows to reach very high peak pressures on the front surface of the targets, up to about $150 \mathrm{GPa}$ (1.5 Mbar). Such strong shocks produce the spallation of the metallic samples, which creates a typical pull-back signal on the records. The results are compared to the predictions of computer simulations including a spall model. Three types of comparisons can be made between computations and experiments : (i) peak current delivered by the transducers, (ii) temporal shape of the records, including recompression waves due to spallation, and (iii) damage distribution in the spalled targets.

\section{EXPERIMENTAL}

The experiments have been performed in the Centre CEA-LV, with the auxiliary beam of the laser Phébus. The maximum available energy is $1.5 \mathrm{~kJ}$; the wavelength is $1.05 \mu \mathrm{m}$; the temporal shape of the laser pulse is close to a square; its duration at half maximum is about $1.5 \mathrm{~ns}$. Piezoelectric transducers made of poly(vinylidene-fluoride-trifluoroethylene) copolymer $\mathrm{P}(\mathrm{VDF} / \mathrm{TrFE})$ are stuck on the rear surface of the irradiated targets, and the assembly is set in vacuum. The diameter of the irradiated spot, greater than 4 
$\mathrm{mm}$, is considerably larger than the target and transducer thicknesses, which ensures uniaxial wave propagation over the center region of the beam path during the measurement. The experimental set-up is described in more details elsewhere [10].

When the laser-driven shock is transmitted from the target into the copolymer, it produces a jump in the output current, whose amplitude can be related to the peak pressure induced in the transducer. Meanwhile, a release wave is reflected back into the target, because of the impedance mismatch between the two materials. When that release wave interacts with the incident unloading wave, tensile stresses are induced inside the target. For laser irradiances higher than about $1 \mathrm{TW} / \mathrm{cm}^{2}$, that local tension is intense enough to cause spallation. In that case, recompression waves propagate from the spall plane, and their transmission into the polymer produces additional peaks in the record after the initial jump. Finally, when the main shock reaches the rear surface of the transducer, it produces a negative jump in the current Typical gauge records will be shown and discussed in section 4 .

The spalled samples have been recovered, embedded in a resin, then cut through a plane containing the axis of the laser. The section surfaces have been polished and observed in optical microscopy. The spallation process inferred from the measurements has been confirmed, and a range of damage levels has been observed, from incipient spall to void coalescence. Micrographs will be presented in section 4 .

\section{COMPUTATIONS}

Computer simulations of the experiments have been carried out, involving two one-dimensional lagrangian hydrocodes. Provided the temporal profile of the laser irradiation measured for each shot, the history of the pressure induced near the front surface of the target can be computed with the laser-matter interaction code FILM [11] from the LULI (UMR 100, Ecole Polytechnique). Then, that pressure history can be applied as an input condition for the wave-propagation code SHYLAC $[1,4,6]$ developed in LCD. A phenomenological spall model proposed by Kanel [12-15] has been added in that latter code. It involves three phenomenological parameters, among which a viscosity $k$ that has been shown to increase with the deformation rate [15]. The values used in our computations are listed in Table 1 . They are close to those given by Tollier $[14,15]$. A simple piezoelectric model has been used to calculate the instantaneous response of the polymeric transducer [8-10].

Thus, for each experiment, the computed response can be compared to the actual record. Matching the complete profile is a severe test for the models, because it implies a good agreement on the laser-shock loading, on the transit times of the waves in the target-transducer assembly, on their decay, on the spall damage in the target and on its influence upon the stress history. Moreover, the location and quantity of damage predicted by the simulations can be compared to the micrographs of the recovered samples.

Table 1 : Spall model parameters used for aluminum and copper

\begin{tabular}{|c|c|c|}
\cline { 2 - 3 } \multicolumn{1}{c|}{} & aluminum & copper \\
\hline threshold tensile stress for damage $\sigma_{1}$ & $1.5 \mathrm{GPa}$ & $2.5 \mathrm{GPa}$ \\
material viscosity $\mathrm{k}$ & $2 \mathrm{~Pa}^{-1} \mathrm{~s}^{-1}$ & $2 \mathrm{~Pa}^{-1} \mathrm{~s}^{-1}$ \\
critical relative void volume $\mathrm{V}_{\mathrm{C}}$ & 0.03 & 0.015 \\
\hline
\end{tabular}

\section{RESULTS}

\subsection{Peak current on the records}

The measured (dots) and computed (shaded areas) peak currents delivered by the transducers are plotted versus laser intensity in figure 1 . Several types of transducers have been used (thickness, composition, polarization, crystallinity...). For convenience, we have normalized all the currents as if they had been obtained with the upgraded $490 \mu$ m-thick elements of P(VDF/TrFE) (77\% / 23\% in mole), electrodedeposited in a guard ring configuration, with a $4 \mathrm{~mm}^{2}$ active area and a piezoelectric constant $\mathrm{K}=5.3$ $\mu \mathrm{C} / \mathrm{cm}^{2}[10]$. For a given irradiance, the shock transmitted into the transducer is stronger for aluminum 
than for copper, because of the different impedance mismatch between the metallic target and the copolymer. In our experiments, the amplitude of that transmitted shock varies between $1 \mathrm{GPa}$ and 13.7 $\mathrm{GPa}$ in the copolymer. Scattering in the computations is due to slight variations in the temporal shape of the laser pulse. Scattering in the measurements may come from the determination of the irradiated area on the target, or from the influence of the thin layer of resin between the target and the copolymer. The discrepancies between measured and computed currents can be attributed to the same experimental uncertainties, as well as to the modelling assumptions (simple constitutive laws for the materials, approximate description of the piezoelectric behaviour of the polymer), a good overall coherence is observed. According to the FILM computations, the peak pressures induced on the irradiated surfaces of the targets vary from $7.5 \mathrm{GPa}\left(0.19 \mathrm{TW} / \mathrm{cm}^{2}\right)$ to $152.3 \mathrm{GPa}\left(7.19 \mathrm{TW} / \mathrm{cm}^{2}\right)$, and they do not differ much between aluminum and copper.

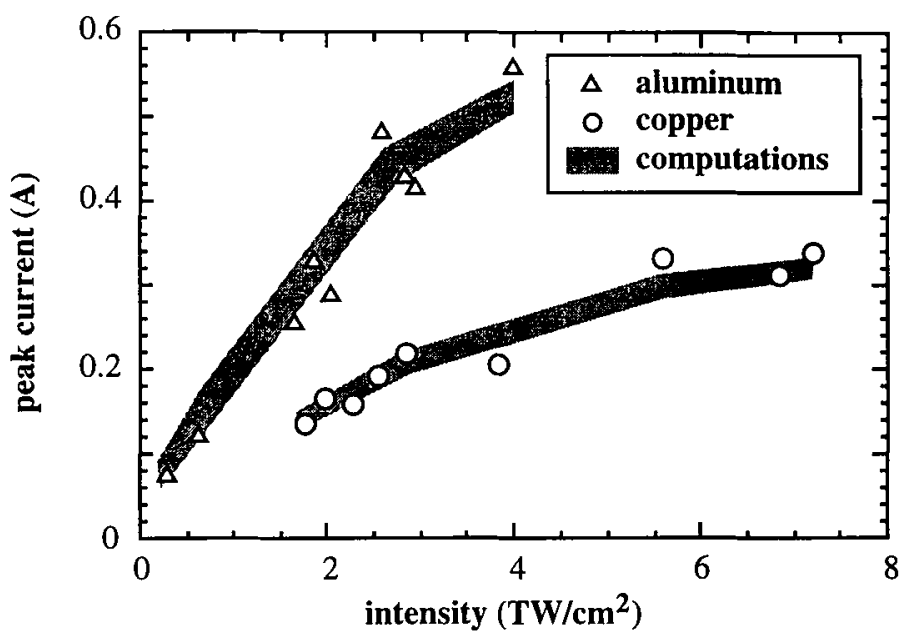

Figure 1: Peak current delivered by the polymeric transducers vs. laser intensity : triangles and round dots refer respectively to aluminum targets and copper targets; shaded areas show the computed results.

\subsection{Spall signal on the records}

Figure 2 shows a typical signal delivered by a $490 \mu$ m-thick copolymer element placed behind a $435 \mu \mathrm{m}$ thick aluminum foil irradiated by a laser pulse of $2.07 \mathrm{TW} / \mathrm{cm}^{2}$. It matches the general description of section 2. Two simulations, with and without spall calculations, are plotted on the same graph (dotted and mixed lines). The plasma created by the laser irradiation produces a strong parasitic noise at time $t=0$. The laser shock is transmitted into the transducer at time $t \sim 70 \mathrm{~ns}$ (positive jump in the output current), and it reaches the rear surface of the transducer at time $\mathrm{t} \sim 218 \mathrm{~ns}$ (negative jump). The measured and computed peak currents are in good agreement, as well as the transit times in both target and transducer. As expected for such high irradiance, fracture produces compression and release waves that reverberate between the spall plane and the rear surface of the target. Their transmission into the transducer leads to several peaks in the release following the main shock (times $\sim 90 \mathrm{~ns}, 110 \mathrm{~ns}, 130 \mathrm{~ns}$, etc...). Spallation is confirmed by the micrograph of the cross section shown in figure 3 . The planarity of the damaged zone shows the homogeneity of the energy distribution over the irradiated spot, and assesses the validity of our planar propagation assumption near the axis of the laser beam. The peaks are rather well reproduced by the spall model, even though the computed response stays significantly below the record. That discrepancy has been observed for all shots. It is probably due to non-linear effects in the piezoelectric behaviour of the transducers under high compression [16], neglected in the calculations. The damage might also be slightly under-estimated by the spall model.

Figure 4 shows another signal recorded behind a $495 \mu \mathrm{m}$-thick copper foil irradiated by a laser pulse of $6.84 \mathrm{TW} / \mathrm{cm}^{2}$. The corresponding cross section is shown in figure 5. Like in figure 2, a correct 
overall agreement between the measured and computed responses is observed. Such agreement has been obtained over the whole explored range. However, for lower laser intensities leading to incipient damage, the computation fits the signal better when using a lower value for $\mathrm{k}$ [17].

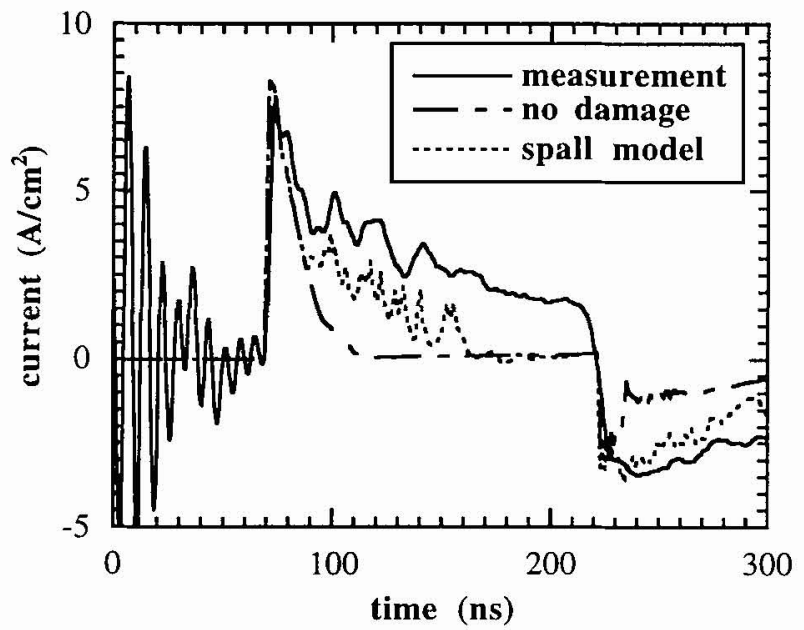

Figure 2 : Response of a $490 \mu \mathrm{m}$-thick copolymer transducer stuck behind a $435 \mu \mathrm{m}$-thick aluminum foil irradiated with a $2.07 \mathrm{TW} / \mathrm{cm}^{2}$ intensity (solid line). Additional peaks in the record indicate spallation, which is confirmed in figure 3 . The dotted and mixed lines show the computed responses, with or without accounting for spallation.

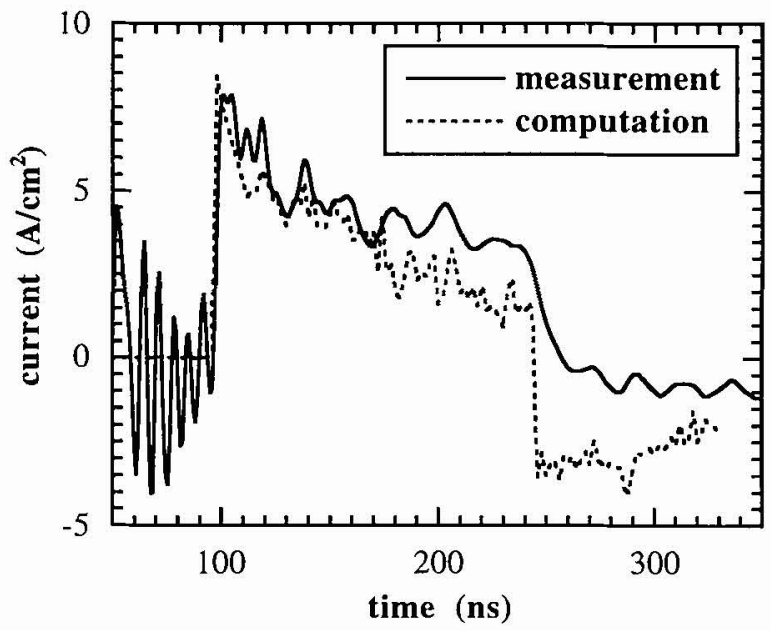

Figure 4: Comparison of the measured (solid line) and computed (dotted lines) responses of a $490 \mu \mathrm{m}$-thick copolymer transducer stuck at the back of a $495 \mu$ m-thick copper foil submitted to a laser intensity of $6.84 \mathrm{TW} / \mathrm{cm}^{2}$.

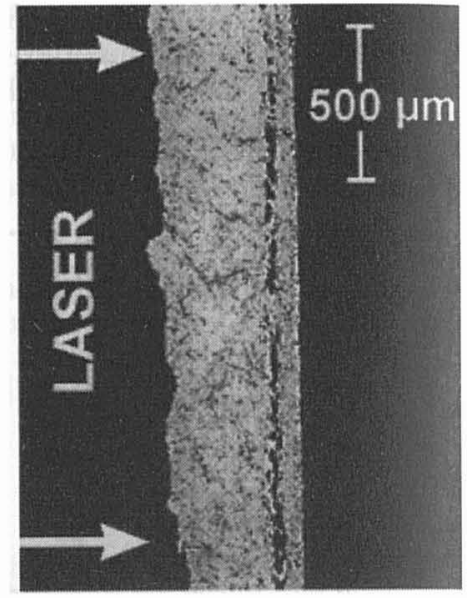

Figure 3: Micrograph of the cross section of a $435 \mu \mathrm{m}$-thick aluminum target submitted to a laser shock of 2.07 $T W / \mathrm{cm}^{2}$, showing spall damage. The corresponding record is shown in figure 2.

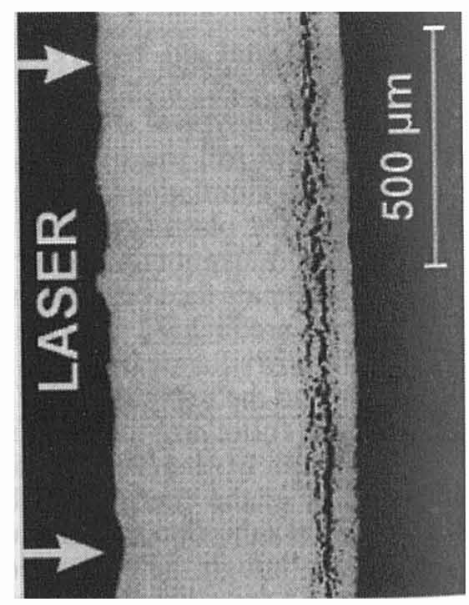

Figure 5: Micrograph of a $495 \mu$ m-thick copper target submitted to a laser shock of $6.84 \mathrm{TW} / \mathrm{cm}^{2}$, showing spall damage. The corresponding record is shown in figure 4 . 


\subsection{Spall damage in the targets}

Figure 6 shows a comparison between the relative void volume computed throughout the target at the end of the calculation of figure 2 and the qualitative damage observed on the micrograph of figure 3 . In all our computations, the relative void volume in the damaged cells has been limited to $44 \%$, in order to avoid a drastic reduction of the time step [15]. Therefore, the corresponding threshold on the graph has no physical meaning. Nevertheless, the model provides a realistic estimate for the damage location in the target.

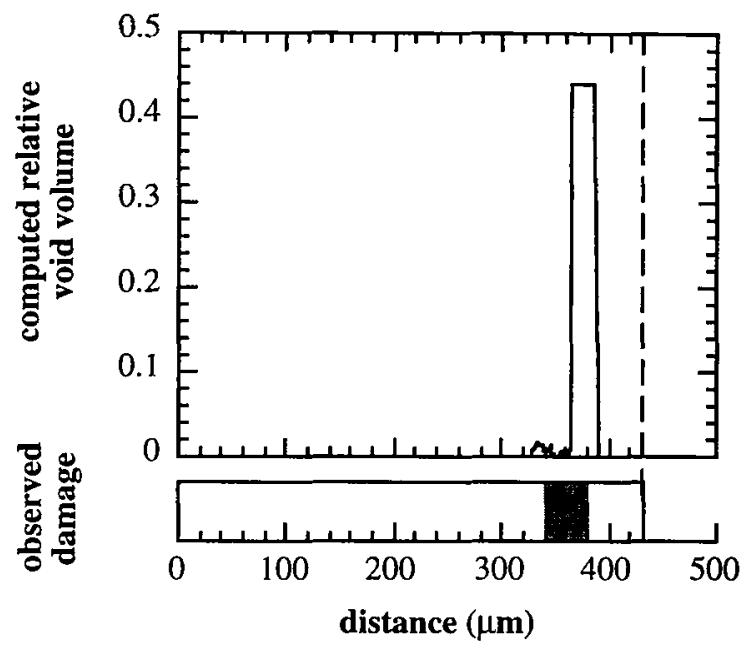

Figure 6: Comparison of the void distribution computed along the direction of propagation in the $435 \mu \mathrm{m}$ thick aluminum target of figures 2 and 3 and the damage estimated qualitatively on the cross section.

\section{CONCLUSION}

In-situ measurements using recently developed polymeric transducers have been performed to characterize short laser-driven shocks over a wide range of intensities, previously unexplored with such technique. The signals recorded for laser intensities above $1 \mathrm{TW} / \mathrm{cm}^{2}$ present a typical peak associated to a spallation process, that can be confirmed by the post-test examination of the recovered targets.

The experimental data have been used to check the capability of numerical models to predict (i) the mechanical effect of laser irradiation, (ii) the propagation of compression and release waves in solid materials, (iii) the spallation process under tensile loading and the resulting stress relaxation in the damaged samples. An overall coherence between computations, measurements and post-test observations has been obtained on the explored range. That agreement assesses the predictive capability of both the FILM and SHYLAC codes. However, significant discrepancies remain on the detailed temporal shape of the records. Those discrepancies probably reveal the limits of the simple constitutive laws and spall model involved in the simulations. On the other hand, they could partly come from experimental uncertainties, such as the possible influence of non-linear effects in the piezoelectric behaviour of the polymeric transducers. Therefore, more work is needed to accurately characterize that behaviour under high dynamic compression. 


\section{Acknowledgements}

We thank all the staff of E.I.L. in C.E.A.-L.V. where the laser experiments have been made, as well as F. Bauer and his team in I.S.L. for providing us with piezoelectric materials, and J.C. Gauthier in L.U.L.I. for letting us run the FILM code.

\section{References}

[1] Cottet F. and Boustie M., J. Appl. Phys. 66 (11), 4067 (1989)

[2] Eliezer S., Gilath I., Bar-Noy T., J. Appl. Phys. 67 (2), 715 (1990)

[3] Eliezer S., Gazit Y., Gilath I., J. Appl. Phys. 68 (1), 356 (1990)

[4] Boustie M. and Cottet F., J. Appl. Phys. 69 (11), 7533 (1991)

[5] Lacomme M., Cazalis B., David J., Niérat G., Salères A. and Sibille G., Journal de Physique IV, Colloque C8, Supplément au Journal de Physique III, Vol. 4 (1994)

[6] de Rességuier T. and Cottet F., J. Appl. Phys. 77 (8), 3756 (1995)

[7] Bauer F., Isner-Brom P., Moulard H., Couturier S., de Rességuier T., Boustie M., in A.P.S. proceedings (Seattle, August 1995)

[8] Moulard H. and Bauer F., in H.D.P. proceedings, p. 327 (Tours, France, June 1995)

[9] Couturier S., de Rességuier T., Hallouin M., Romain J.P., Bauer F., J. Appl. Phys. 79 (12), 9338 (1996)

[10] de Rességuier T., Couturier S., Boustie M., David J., Niérat G., Bauer F., J. Appl. Phys. 80 (6) (1996)

[11] Atzeni S., Plasma Physics and Controlled Fusion 29, 11 (1987)

[12] Kanel G.I., Fortov V.E., Adv. Mech., 10 (3) (1987)

[13] Fortov V.E., Kostin V.V., Eliezer S., J. Appl. Phys. 70 (8), 4524 (1991)

[14] Tollier L., Bartnicki E., Fabbro R., in A.P.S. proceedings (Seattle, August 1995)

[15] Tollier L., Thèse de Doctorat de I'Université de Poitiers (1996)

[16] Couturier S., de Rességuier T., Hallouin M., Bauer F., submitted to Shock Waves in 1996

[17] de Rességuier T., Couturier S., David J., Niérat G., submitted to J. Appl. Phys. in 1996 